\title{
Grinding-induced metallurgical alterations in the binder phase of WC-Co cemented carbides
}

\author{
J. Yang ${ }^{1,2}$, J.J Roa ${ }^{1,3}$, M. Schwind ${ }^{4}$, M. Odén ${ }^{2}$, \\ M.P. Johansson-Jõesaar ${ }^{2,4}$ and L. Llanes ${ }^{1,3}$ \\ ${ }^{1}$ CIEFMA - Departament de Ciència dels Materials i Engenyeria Metal·lúrgica, Campus Diagonal Besòs-EEBE, \\ Universitat Politècnica de Catalunya, Barcelona 08019, Spain \\ 2 Nanostructured Materials, Department of Physics, Chemistry, and Biology (IFM), Linköping University, \\ Linköping 58183, Sweden \\ ${ }^{3}$ Universitat Politècnica de Catalunya, Research Center in Multiscale Science and Engineering, Campus Diagonal \\ Besòs - Edif. DBC, Av. d'Eduard Maristany, 10-14, 08019 Barcelona, Spain \\ ${ }^{4}$ SECO Tools AB, Fagersta 73782, Sweden
}

\begin{abstract}
The metallic binder phase dictates the toughening behavior of WC-Co cemented carbides (hardmetals), even though it occupies a relative small fraction of the composite. Studies on deformation and phase transformation of the binder constituent are scarce. Grinding represents a key manufacturing step in machining of hardmetal tools, and is well-recognized to induce surface integrity alterations. In this work, metallurgical alterations of the binder phase in ground WC-Co cemented carbides have been assessed by a combination of electron back scattered diffraction and transmission electron microscopy techniques. The Co-base binder experiences a martensitic phase transformation from fcc to hcp crystal structure, predominantly in the first $5 \mu \mathrm{m}$ below the surface. The hcp fraction decreases gradually along a depth of $10 \mu \mathrm{m}$. Surface Co displays severe plastic deformation under the highest strain, resulting in formation of nanocrystalline grains in the first micrometer below the surface. Microstructural refinement within the binder phase is observed even at greater depth. Stacking faults were detected in most of the refined grains. The metallurgical alterations of the binder phase modify the local stress distribution during grinding, which affects the discerned subsurface microcracking. The resulting residual stress profile is the sum of multiple subsurface changes, such as phase transformation, severe plastic deformation and grain refinement, where it is discerned that the depth profile of the transformed hcp-Co fraction coincides with the grinding-induced residual stress profile.
\end{abstract}

Keywords: Grinding; WC-Co cemented carbides; metallic binder; deformation; phase transformation 


\title{
Grinding-induced metallurgical alterations in the binder phase of WC-Co cemented carbides
}

\begin{abstract}
The metallic binder phase dictates the toughening behavior of WC-Co cemented carbides (hardmetals), even though it occupies a relative small fraction of the composite. Studies on deformation and phase transformation of the binder constituent are scarce. Grinding represents a key manufacturing step in machining of hardmetal tools, and is well-recognized to induce surface integrity alterations. In this work, metallurgical alterations of the binder phase in ground WC-Co cemented carbides have been assessed by a combination of electron back scattered diffraction and transmission electron microscopy techniques. The Co-base binder experiences a martensitic phase transformation from fcc to hcp crystal structure, predominantly in the first $5 \mu \mathrm{m}$ below the surface. The hep fraction decreases gradually along a depth of $10 \mu \mathrm{m}$. Surface Co displays severe plastic deformation under the highest strain, resulting in formation of nanocrystalline grains in the first micrometer below the surface. Microstructural refinement within the binder phase is observed even at greater depth. Stacking faults were detected in most of the refined grains. The metallurgical alterations of the binder phase modify the local stress distribution during grinding, which affects the discerned subsurface microcracking. The resulting residual stress profile is the sum of multiple subsurface changes, such as phase transformation, severe plastic deformation and grain refinement, where it is discerned that the depth profile of the transformed hcp-Co fraction coincides with the grinding-induced residual stress profile.
\end{abstract}

Keywords: Grinding; WC-Co cemented carbides; metallic binder; deformation; phase transformation 


\section{Introduction}

WC-Co cemented carbides, often referred to as hardmetals, are the backbone materials of the tool manufacturing industry [1-3]. Their technological success is directly related to the fact that they microstructurally consist of two interpenetrating phases: hard/brittle carbides and a soft/ductile metallic binder, with optimal interface properties $[4,5]$. As a result, and depending on their microstructure, they exhibit outstanding combinations of hardness and fracture toughness. On the other hand, prescribed dimensional accuracy combined with particular geometries are frequent requirements for hardmetal tools. In this regard, and considering the relative high hardness of WCCo cemented carbides, diamond wheel grinding is the primary shaping process for these materials $[1,6,7]$. However, similar to other hard and brittle materials [8-10], as a result of the abrasive operation, surface integrity of hardmetals is altered at both surface and subsurface levels, particularly in terms of microcracks, residual stresses, and metallurgical alterations within the metallic binder. Thus, mechanical and tribological performance of corresponding tools and components are also affected [6, 11-19].

In spite of the relatively small fraction of the binder phase within cemented carbides (commonly between 3 and $30 \mathrm{wt} \%$ in commercial grades), this constituent is responsible for the exceptional toughening behavior exhibited by these materials. In this regard, plastic stretching of crackbridging binder enclaves developed in the wake of extending cracks $[20,21]$ results in an enhanced crack growth resistance, which yields not only higher toughness values but also reduces the strength scatter [22, 23]. Within this context, fracture mechanics and mechanisms related to crackmicrostructure interactions in hardmetals, under both monotonic and cyclic loading, are now wellestablished and understood [20-25]. On the other hand, the plastic deformation mechanisms within the metallic binder, when hardmetals are subjected to external loads, have been given less attention [26-30]. This is particularly true in the case of alterations induced by grinding and scratching, i.e. under sliding contact service-like conditions. The existing information is scarce and mainly focused on either changes within the hard and brittle carbides or generic composite-related damage, such as microcracks developed at both surface and subsurface levels (e.g. Refs. [6, 31]).

Assessment of structural changes in the binder phase of cemented carbides is complex. The minority phase is present in the microstructure as thin layers (usually less than $1 \mu \mathrm{m}$ thick) between 
carbides particles. This type of microstructure also implies a marked variation in the local deformation structure and residual microstress [30, 32-35]. The significantly different hardness of the ceramic and metallic constituents yields distinctly different material removal rates of the two phases during abrasive grinding. Such dispersed behavior imposes additional difficulties when extracting samples for electron microscopy.

The main deformation mechanism for fcc stabilized $\mathrm{Co}$ is reported to be martensitic phase transformation to the room temperature stable hcp phase [26-30]. In order to characterize the structural changes induced by grinding in the Co-phase, two complementary characterization techniques: transmission electron microscopy (TEM) and electron back-scatter diffraction (EBSD), are employed in this study. They have previously been proven to be well-suited to characterize structural changes in cemented carbides [26-30, 36-39]. Specifically, we report nearsurface cross-sectional analyses of ground specimens, showing metallurgical alterations of the binder phase and correlate the results to grinding-induced changes (e.g., microcracking and residual stresses).

\section{Experimental procedure}

The hardmetal studied in this work is a WC- $13 \mathrm{wt} . \%$ Co grade with a carbide mean grain size of $0.7 \mu \mathrm{m}$. Vickers hardness and fracture toughness are assessed as $14.8 \mathrm{GPa}$ and $11.2 \mathrm{MPa} \sqrt{\mathrm{m}}$ respectively [40]. Ground specimens $(\mathrm{G})$ were attained following an industrial grinding routine. It was implemented by means of a commercial abrasive diamond wheel while the surface was sprayed with a coolant to minimize heat generation. A mirror-like polished sample of the same grade $(\mathrm{P})$ was used as reference. It was obtained through sequential mechanical polishing stages, finishing with one involving silica colloidal suspension.

Aiming for a surface finish suitable for EBSD inspection, an alternative surface preparation route was followed. First, a section was cut through the surface of the sample, aiming to exposure a cross-sectional area of at least $5 \times 5 \mathrm{~mm}^{2}$. The area of interest was then mechanical polished sequentially with finer and finer diamond grits (final grit size $1 \mu \mathrm{m}$ ). Finally, the cross-sectional area was argon ion milled in a cross-section polisher (mode JOEL SM-09010) at $6 \mathrm{keV}$ and a mean beam current of $30 \mu \mathrm{A}$. EBSD data acquisition was performed using a Zeiss Sigma FEG SEM at 
$20 \mathrm{kV}$ acceleration voltage. The specimen was tilted $70^{\circ}$ against the electron beam. Data were collected across an area $30 \times 20 \mu \mathrm{m}^{2}$ in size, with a step size ranging between $31-35 \mathrm{~nm}$. Crystallographic and orientation maps were constructed by using the Channel 5 software.

Foils suitable for TEM examination were prepared using FIB (dual beam Zeiss Neon 40 work station) by means of pre-thinning and a lift-out technique. Before milling, a protective and stripshaped Pt layer was deposited, with its long direction orthogonal to the grinding-grooves, on the surface region of interest. Afterwards, two adjacent square blocks $\left(10 \times 10 \mu \mathrm{m}^{2}\right)$ were milled out of the surface using $30 \mathrm{kV} \mathrm{Ga}^{+}$ions, yielding as result a thin membrane. Then, subsequent milling series were performed until the referred membrane became electron-transparent. The final dimensions of the foil were approximately $7 \mu \mathrm{m}$ in width, $10 \mu \mathrm{m}$ in depth and $60 \mathrm{~nm}$ in thickness.

Substructural characterization was performed in a TEM (JEOL J2100Lab6) operated at $200 \mathrm{kV}$. Besides TEM imaging and selected area electron diffraction (SAED), precession electron diffraction-assisted automated crystal orientation mapping (PED-ACOM) was also performed. The latter was done using ASTAR/DigiSTAR from NanoMEGAS and software package. PEDACOM provides full crystallographic information of the material at a specific region of interest, with a point spread resolution with the nanometer range [41, 42].

\section{Results}

\subsection{Grinding-induced phase transformation in the Co phase}

Combined cross sectional EBSD phase and band contrast maps of the ground sample and (for comparison) the reference polished one are shown in Fig. 1a and 1b, respectively. WC grains are presented in greyscale, determined by the band contrast map of the EBSD patterns. Red and blue color scales are used to dispaly Co phases indexed as fcc and hcp, respectively. The fraction indexed as fcc and hcp (after clean-up) for the ground sample are $9.55 \%$ and $3.25 \%$, respectively. The fraction indexed as hcp for the reference $\mathrm{P}$ sample is negligible while $14.10 \%$ is indexed as fcc. The obtained Kikuchi patterns from the Co-phases are distinct and almost without any shadowing effects, which resulted in accurate indexing. It indicates that the surface preparation 
method used, particularly the last low energy ion etch step, is suitable to produce the needed surface quality. Direct comparison of Fig. 1a and $\mathbf{1 b}$ points out that grinding induces a transformation of the binder from the original stabilized fcc phase to hcp one. This is supported by the fact that the hcp phase is mainly concentrated in the region most affected by grinding, i.e. 0 to $5 \mu \mathrm{m}$ below the surface. Its presence decreases with depth, and at $10 \mu \mathrm{m}$ below the surface, individual hcp grains are occasionally observed (Fig. 1a).

Fig. 2 shows inverse pole figure (IPF) coloring map for the Co phases (fcc and hcp) overlaid to the band contrast image (Fig. 2a). IPF coloring maps for fcc and hcp Co phases are shown in Fig. 2b and Fig. 2c, respectively. In Fig. 2b, it can be discerned that areas with similar crystallographic orientations are larger than the WC grains and the individual Co regions. It suggests a large Co skeleton that penetrates the WC network, in agreement with previously reported findings [37]. Note that dotted lines drawn in the figure are intended as for visual description, but they do not correspond to Co grain boundaries. In fact, the Co skeleton itself is expected to consist of grains penetrating each other [37]. For example, the two large Co regions with crystallographic orientations indexed as pink and blue (the lower left one and the upper one) in Fig. $2 \mathbf{b}$ are interpenetrated inside a small region looped with the solid line at the left bottom corner. Fig. 2c shows that hcp Co phase is concentrated in the first $5 \mu \mathrm{m}$ below the surface. When correlating the location of the hep phase with fcc regions in Fig. 2b, it indeed corresponds to the blue fcc Co region, indicating that the hcp Co was mainly transformed from there. Aiming at more clearly revealing this transformation relationship, the same dotted line corresponding to the blue fcc Co region in Fig. 2b was copied into Fig. 2c. The fcc Co grain with a single orientation has partly transformed to hcp with at least three different orientations, depicted as blue, purple and red. The size of the hcp Co grain is also larger than the WC particles.

In order to reveal the transformation process in more detail, pole figures (PF) of the crystallographic directions of the Co-phases in the region from 0 to $5 \mu \mathrm{m}$ below the surface are illustrated in Fig. 3. The strong correlation between the PF of Co fcc (111) and hcp (0001) points out a crystallographic relationship between parent fcc phase and the new hcp one. It also implies that all the hcp regions detected stems from one single fcc grain. 


\subsection{Grinding-induced metallurgical alterations of the Co phase}

Fig. 4 presents crystal orientation and phase mapping results of a cross section extending $3 \mu \mathrm{m}$ below the ground surface. A combined phase and reliability map is given in Fig. 4a. There, a dotted line has been added to distinguish the Pt protective layer from the material of interest. Red, blue and green colors represent WC, fcc Co and hcp Co phases, respectively. The majority of the detected Co corresponds to the hcp structure, which is consistent with the data attained by means of EBSD. Fig. 4b shows a correlation index map that reveals a bimodal structure (small crystals) inside the metallic binder, formed during grinding. This is particularly clear in the areas just underneath the surface. In order to reveal this highly deformed binder phase region clearer, a map only containing Co binder is given in Fig. 4c (corresponding to the dotted rectangular area in Fig. 4b). It indicates that grinding leads to grain refinement of the binder phase, with crystal sizes lower than $100 \mathrm{~nm}$. The binder phase is plastically deformed in this region causing substantial crystallographic misorientation. The latter makes orientation maps only possible for the WC phase (Fig. 4d). From such maps it is clear that WC grains, down to $\sim 500 \mathrm{~nm}$ depth, experience fragmentation due to grinding.

Fig. 5a shows the microstructure observed by TEM of the region near the surface, where the metallic binder was highly deformed by the grinding process. The bright and dark contrast correspond to Co and WC phase, respectively. SAED pattern (Fig. 5b) recorded from the area indicated by a circle in Fig. 5a shows random orientation of the Co grains. Fig. 5c and d show regions of the deformed Co region at two magnifications. A large number of nanocrystalline (nc) grains are present, with a grain size smaller than $20 \mathrm{~nm}$. Furthermore, dislocations and stacking faults (SF) are present in the small grains, marked with red arrows in Fig. 5d.

Fig. 6a shows the microstructure $2 \mu \mathrm{m}$ below the ground surface. Some slip traces (see white arrow in Fig. 6a) are evident inside the WC grain. The SAED pattern (Fig. 6b) taken from the marked circular area in Fig. 6a shows a quasi-ring feature with streaks at each diffraction spot. It also points out a random distribution of crystallographic orientations but less intense than the one shown in Fig. 5b. This suggests that the grains located at this depth are also refined, but down to a coarser structure, as compared to the one assessed just below the surface. These observations indicate that severe deformation during grinding induces grain refinement at least until this depth, 
and fades with increasing distance to the surface. Another image taken at higher magnification (Fig. 6c) illustrates more clearly microstructural aspect of the highly deformed Co phase.

Overlaid phase, local crystallographic, and reliability TEM maps recorded from a region 5 to $8 \mu \mathrm{m}$ below the ground surface are shown in Fig. 7. In the phase map shown in Fig. 7a, red, blue and green colors represent $\mathrm{WC}$, fcc Co and hcp Co phases, respectively. In this region, phase transformation from fcc to hep has not occurred homogenously, and some parts of the Co region remain in the fcc structure. The lower amount of hcp Co at this depth is expected, since the grinding induced plastic strain and strain rate is lower compared to the regions closer to the surface. Fig. 7b, $\mathbf{c}$ and $\mathbf{d}$ show orientation maps of WC, fcc Co and hcp Co, respectively. In each WC grain, the crystallographic orientation is nearly homogeneous, pointing out neither subdivision nor fracture of the WC grains. Fcc Co revealed in Fig. 7c, illustrates a simple crystallographic feature, as the main two fcc Co grains exhibited a homogenous green color, indicating one orientation close to the [101] direction. Neither subdivision of grains nor twins in the fcc Co were observed within the area mapped. In Fig. 7d, four separated hcp Co regions at various depths are marked as (1), (2), (3) and (4). Similar to EBSD technique, TEM-PED mapping also allows to measure the misorientation angle between two grains. Inside hcp Co region (3), the misorientation angle between the blue lath (around $70 \mathrm{~nm}$ thick) and the neighboring green grain is about $71^{\circ}$. On one hand, according to this orientation change and the platelet-like morphology, it could be expected that blue lath yields from deformation twinning as a mode to accommodate the strain [43]. On the other hand, since it has been established that (1) the hcp Co phase results from transformation from the fcc phase, and (2) the crystallographic angle between two different $\{111\}$ planes of fcc structure is $71^{\circ}$, it should be expected that crystallographic angle between two different $\{0001\}$ planes coming from two different regions of hcp Co is $71^{\circ}$. Hence, the angular difference observed does not necessarily have to be the result of twinning deformation. Further analysis shows that crystallographic orientation difference in two neighboring grains inside hcp Co regions (1) and (2) were also $71^{\circ}$. Moreover, the shape of these hcp region was seldom recognized as platelet-like. Instead, the hcp Co grains found here, with a distinct misoreintation angle, mostly originate from different sets of $\left\{\begin{array}{lll}1 & 1 & 1\end{array}\right\}$ planes, rather than from deformation twins. Based on the above characterization, the microstructural features of the Co phase are summarized in Table 1. 


\section{Discussion}

Grinding is a harsh percussive repetitive abrasive action against the surface of a material. It leads to cumulative deformation in the near surface region. In general, deformation mechanisms include plastic deformation through slip and twinning, phase transformation, cracking, etc. It may alter the residual stress state and grain size at the subsurface. The deformation occurring in the WC-Co hardmetal, with emphasis on alteration in the binder phase, will be first discussed. Then, a correlation of such deformation scenario to changes in the residual stress state and formation of cracks will be finally proposed.

\subsection{Phase transformation and plastic deformation of the Co binder}

In as-sintered condition, the Co-base binder within hardmetals is normally a fcc solid solution containing W, C and other elements [5]. This is favorable from a performance viewpoint, since a more ductile and fracture resistant material is achieved with the fcc phase than with the hcp one. Besides affecting crack-growth resistance (toughness), the binder phase also influences the fatigue and magnetic properties of hardmetals [5, 30, 44, 45]. A martensitic phase transformation of the Co phase (from fcc to hcp) may occur when it is plastically deformed [26-28, 43, 46]. The observed SFs in as-sintered material are expected, since they lower the free energy of both fcc and hcp structures compared to SF-free ones $[43,46]$. The numerous stacking faults present in the undeformed fcc binder may act as nucleation planes for hcp lamella formation. As the deformation continues, SFs simply increase their thickness and subsequently coalesce to form observable hcp lamellae. This may take place by gliding appropriate Shockley partials on every second (111) plane of fcc structure [26]. The allotropic transformation resulted in large hcp platelets, which have coherent interfaces with the parent fcc crystal, according to the following orientation relationships: $(0001)_{\mathrm{hcp}} / /\left\{\begin{array}{lll}1 & 1 & 1\end{array}\right\}_{\mathrm{fcc}}$ and $\langle 11 \overline{2} 0\rangle_{\mathrm{hcp}} / /\langle 110\rangle_{\mathrm{fcc}}$. This implies a maximum of four orientations of the hcp platelets in each grain of the binder.

Grinding induced severe plastic deformation of the Co in the near surface region, and it resulted in refinement of the binder grains. The refinement was more pronounced close to the surface where the strain was high, i.e. formation of nanocrystalline grains down to a depth of around $1 \mu \mathrm{m}$. It also resulted in an ultrafine grain microstructure just below this subsurface level. Previous studies on cemented carbides under monotonic/cyclic compression and flexure loading have reported SFs 
formation, fcc twining, and phase transformation ( $\mathrm{fcc} \rightarrow \mathrm{hcp}$ ) of the Co-base binder [26-28, 30, 44, 47]. However, to the best knowledge of the authors, formation of nanocrystalline grains has not been ever reported. Grain refinement is reported by $\mathrm{Wu}$ et al. [43, 48] during surface mechanical attrition treatment of bulk Co. In such studies, dominant grain refinement mechanism was suggested to be grain subdivision through both prismatic $\langle 11 \overline{2} 0>\{1 \overline{1} 00\}$ and basal $<11 \overline{2} 0\rangle$ (0001) slip. Deformation modes in bulk Co are expected to be comparable with those existing in the binder phase of the composites, although appreciable difference in grain size, solute addition, residual stresses, and WC constraint do exist. In this sense, dislocations cause formation of low angle subboundaries and formation of subgrains. The misorientation rises with increasing strain, resulting in finer microstructures, down to ultrafine- and nano-crystalline structures. Further straining results in grain rotation and grain boundary sliding, yielding finally a completely randomoriented microstructure.

\subsection{Correlation of the metallurgical alterations in the metallic binder with crack network and} residual stresses

In recent publications, authors have shown that grinding induced microcracks exist down to a depth of about $2 \mu \mathrm{m}$, and microcracking followed two different microstructural paths: either WC/Co interfaces or transgranular within the carbide phase, whereas the former being more predominant than the latter for the same material and grinding conditions used in the current study $[15,18,19]$. During grinding, the deformation of the Co-base binder is expected to change the local stress state around the diamond grit tip. It affects crack nucleation and propagation phenomena through plastic stretching of crack-bridging binder ligament formation developed in the wake of extending cracks [20, 21]. Sarin and Johannesson's study [26] pointed out that crack formation in WC-Co composites is closely related with the fcc to hcp Co phase transformation. They brought out that since hcp phase only have one easy slip plane, compatibility becomes increasingly difficult as the deformation proceeds. Hence, when a certain fraction of the fcc binder is transformed to hcp, cracks start to form and the carbide skeleton breaks up too. Considering that the results illustrated above shows that hep-Co is observed down to a depth of $5 \mu \mathrm{m}$ in the studied material here, based on their study [26] deeper cracks could be expected. The difference in depth between microcracks and hcp-Co may imply an additional correlation between the evidenced ultrafine microstructure 
and crack formation. Accordingly, it is here proposed that as a consequence of the nanocrystalline microstructure (within the first $3 \mu \mathrm{m}$ at the subsurface), the combination of more frequent stress concentration sites, at dislocation pile-ups within grains and at grain boundaries, and high strain leads to microcrack nucleation. On the other hand, within a coarser microstructure in the region deeper than $3 \mu \mathrm{m}$, dislocation pile-ups can be more extended and the stress concentrations less severe; thus, deformation can be accommodated by slip. Moreover, the fraction of the fcc Co increases with depth, resulting in a more compatible binder as the fcc crystal structure permits to accommodate deformation through dislocation slip and martensitic transformation, without inducing cracks.

The residual stress depth profile for sample $G$ has been reported previously $[15,19]$. The grindinginduced residual stresses extend approximately $12 \mu \mathrm{m}$ below the surface, i.e. well-beyond the cracked zone. The corresponding profile exhibits two defined regimes: one with high compressive stresses down to $6 \mu \mathrm{m}$, followed by another characterized by a sharp stress decrease to baseline values. Residual stress is recognized to be intimately related with the elastic-plastic response of the material upon external loading. As plastic deformation is introduced in the surface layers of the material, residual stresses are locally induced because of the constraining effect of the bulk, where plastic deformation is minimal [49]. Grinding yielded stress field is a multiscratches-like sliding contact with sharp indenters. In the case studied here, the above findings illustrated the multiple changes taken place at the subsurface as sliding contact forces are applied. They include phase transformation, severe plastic deformation and grain refinement. The final residual stress profile should be a compromise of all these subsurface alterations. One interesting point is that residual stress profile coincides with those evidenced for phase transformation phenomenon: high in the first $5 \mu \mathrm{m}$, followed by gradual decrease as it gets deeper into the subsurface, until achieving negligible values below $10 \mu \mathrm{m}$. Considering that Co transformed region is much deeper than that of the severe plastic deformation and grain refinement zone, it is proposed here that residual stress generated by grinding of this hardmetal is intimately related to the volume change associated with the phase transformation within the binder.

\section{Summary}


The metallurgical alterations induced by grinding in the metallic binder of a fine-grade hardmetal system have been assessed. In doing so, an inspection approach including complementary techniques, such as EBSD and TEM, have been used. The following conclusions may be drawn:

- Grinding induces phase transformation of the original fcc structure into the hcp one within the metallic Co binder. The referred phase transformation is mainly concentrated in the 0 $5 \mu \mathrm{m}$ depth region, and relative hcp/fcc phase distribution decreases with depth, down to baseline values at $10 \mu \mathrm{m}$ approximately.

- It is evidenced that severe plastic deformation during grinding yields a relevant microstructural refinement, down to nanoscale values just beneath the surface. A large amount of stacking faults (SF) are present in the small grains. Misorientation angle between two neighboring hcp grains was determined to be $71^{\circ}$.

- The observed metallurgical alterations are suggested to be related to the microcracking scenario discerned at the subsurface (within a layer of $2 \mu \mathrm{m}$ in thickness approximately) of ground specimens. It is speculated that activation of Co deformation modifies the local stress concentration distribution around the diamond grit tip, and affect the crack nucleation phenomenon.

- The depth profile of the transformed hcp-Co fraction coincides with the grinding-induced residual stress profile. The final residual stress profile is proposed to result from a compromise of multiple changes taken place at the subsurface: phase transformation, severe plastic deformation, grain refinement.

\section{Acknowledgements}

Funding for this investigation was partly supplied by the Spanish MINECO/FEDER (Grant No. MAT2015-70780-C4-3-P). One of the authors (J.Y.) acknowledges funding received through Erasmus Mundus joint European Doctoral Programme DocMASE.

\section{References}


[1] Byrne G, Dornfeld D, Denkena B. Advancing cutting technology. CIRP Ann-Manuf Techn. 2003;52:483-507.

[2] Van den Berg H. Hardmetals: trends in development and application. Powder Metall. 2007;50:7-10.

[3] Prakash L. 1.02 - Fundamentals and General Applications of Hardmetals. In: Sarin VK, Mari D, Llanes L (Eds.) Comprehensive Hard Materials. Oxford: Elsevier; 2014. Vol. 1, p. 29-90.

[4] Exner HE. Physical and chemical nature of cemented carbides. Int Met Rev. 1979;24:149-73.

[5] Roebuck B, Almond EA. Deformation and fracture processes and the physical metallurgy of WC-Co hardmetals. Int Mat Rev. 1988;33:90-112.

[6] Bouzakis KD, Michailidis N, Skordaris G, Bouzakis E, Biermann D, M'Saoubi R. Cutting with coated tools: coating technologies, characterization methods and performance optimization. CIRP Ann-Manuf Techn. 2012;61:703-23.

[7] Hegeman JBJW, De Hosson JTM, de With G. Grinding of WC-Co hardmetals. Wear. 2001;248:187-96.

[8] Li K, Warren Liao T. Surface/subsurface damage and the fracture strength of ground ceramics. J Mater Process Technol. 1996;57:207-20.

[9] Rice RW. Monolithic and composite ceramic machining flaw-microstructure-strength effects: model evaluation. J Eur Ceram Soc. 2002;22:1411-24.

[10] Zhang B, Zheng XL, Tokura H, Yoshikawa M. Grinding induced damage in ceramics. J Mater Process Technol. 2003;132:353-64.

[11] M'Saoubi R, Outeiro JC, Chandrasekaran H, Dillon Jr OW, Jawahir IS. A review of surface integrity in machining and its impact on functional performance and life of machined products. Int J Sustain Manuf. 2008;1:203-36.

[12] Merklein M, Andreas K, Engel U. Influence of machining process on residual stresses in the surface of cemented carbides. Procedia Eng. 2011;19:252-7.

[13] Jawahir IS, Brinksmeier E, M'Saoubi R, Aspinwall DK, Outeiro JC, Meyer D, Umbrello D, Jayal AD. Surface integrity in material removal processes: Recent advances. CIRP AnnManuf Techn. 2011;60:603-26.

[14] Breidenstein B, Denkena B. Significance of residual stress in PVD-coated carbide cutting tools. CIRP Ann-Manuf Techn. 2013;62:67-70. 
[15] Yang J, Odén M, Johansson-Jõesaar MP, Llanes L. Grinding effects on surface integrity and mechanical strength of WC-Co cemented carbides. Procedia CIRP. 2014;13:257-63.

[16] Yang J, Roa JJ, Odén M, Johansson-Jõesaar MP, Esteve J, Llanes L. Substrate surface finish effects on scratch resistance and failure mechanisms of TiN-coated hardmetals. Surf Coat Tech. 2015;265:174-84.

[17] Yang J, García Marro F, Trifonov T, Odén M, Johansson-Jõesaar MP, Llanes L. Contact damage resistance of TiN-coated hardmetals: Beneficial effects associated with substrate grinding. Surf Coat Tech. 2015;275:133-41.

[18] Yang J, Odén M, Johansson-Jõesaar MP, Llanes L. Influence of substrate microstructure and surface finish on cracking and delamination response of TiN-coated cemented carbides. Wear. 2016;352-353:102-11.

[19] Yang J, Odén M, Johansson-Jõesaar MP, Esteve J, Llanes L. Mechanical strength of ground WC-Co cemented carbides after coating deposition. Mater Sci Eng A. 2017;689:72-7.

[20] Sigl LS, Exner HE. Experimental-study of the mechanics of fracture in WC-Co alloys. Metall Trans A. 1987;18:1299-308.

[21] Sigl LS, Fischmeister HF. On the fracture toughness of cemented carbides. Acta Metall. 1988;36:887-97.

[22] Tarragó JM, Jiménez-Piqué E, Schneider L, Casellas D, Torres Y, Llanes L. FIB/FESEM experimental and analytical assessment of R-curve behavior of $\mathrm{WC}-\mathrm{Co}$ cemented carbides. Mater Sci Eng A. 2015;645:142-9.

[23] Tarragó JM, Coureaux D, Torres Y, Casellas D, Al-Dawery I, Schneider L, Llanes L. Microstructural effects on the R-curve behavior of WC-Co cemented carbides. Mater Des. 2016;97:492-501.

[24] Shatov AV, Ponomarev SS, Firstov SA. 1.10 - Fracture and strength of hardmetals at room temperature. In: Sarin VK, Mari D, Llanes L (Eds.) Comprehensive Hard Materials. Oxford: Elsevier; 2014. Vol. 1, p. 301-43.

[25] Llanes L, Anglada M, Torres Y. 1.11 - Fatigue of cemented carbides. In: Sarin VK, Mari D, Llanes L (Eds.) Comprehensive Hard Materials. Oxford: Elsevier; 2014. Vol. 1, p. 345-62.

[26] Sarin VK, Johannesson T. On the deformation of WC-Co cemented carbides. Met Sci. 1975;9:472-6. 
[27] Vasel CH, Krawitz AD, Drake EF, Kenik EA. Binder deformation in WC-(Co, Ni) cemented carbide composites. Metall Trans A. 1985;16:2309-17.

[28] Rettenmayr M, Exner HE, Mader W. Electron microscopy of binder phase deformation in WC-Co alloys. Mater Sci Tech. 1988;4:984-90.

[29] Schleinkofer U, Sockel HG, Go“rting K, Heinrich W. Microstructural processes during subcritical crack growth in hard metals and cermets under cyclic loads. Mater Sci Eng A. 1996;209:103-10.

[30] Kursawe S, Pott P, Sockel HG, Heinrich W, Wolf M. On the influence of binder content and binder composition on the mechanical properties of hardmetals. Int J Refract Met Hard Mater. 2001;19:335-40.

[31] Zuñega JCP, Gee MG, Wood RJK, Walker J. Scratch testing of WC/Co hardmetals. Tribol Int. 2012;54:77-86.

[32] Drake EF, Krawitz AD. Fatigue damage in a WC-Nickel cemented carbide composite. Metall Trans A. 1981;12:505-13.

[33] Fischmeister HF, Schmauder S, Sigl LS. Finite element modelling of crack propagation in WC-Co hard metals. Mater Sci Eng A. 1988;105:305-11.

[34] Schleinkofer U, Sockel HG, Görting K, Heinrich W. Fatigue of hard metals and cermets New results and a better understanding. Int J Refract Met Hard Mater. 1997;15:103-12.

[35] Paggett JW, Krawitz AD, Drake EF, Bourke MAM, Livescu V, Claussen B, Brown DW. In situ loading response of WC-Ni: Origins of toughness. Int J Refract Met Hard Mater. 2006;24:122-8.

[36] Mingard KP, Roebuck B, Bennett EG, Gee MG, Nordenstrom H, Sweetman G, Chan P. Comparison of EBSD and conventional methods of grain size measurement of hardmetals. Int J Refract Met Hard Mater. 2009;27:213-23.

[37] Mingard KP, Roebuck B, Marshall J, Sweetman G. Some aspects of the structure of cobalt and nickel binder phases in hardmetals. Acta Metall. 2011;59:2277-90.

[38] Mingard KP, Jones HG, Gee MG, Roebuck B, Nunn JW. In situ observation of crack growth in a WC-Co hardmetal and characterisation of crack growth morphologies by EBSD. Int J Refract Met Hard Mater. 2013;36:136-42. 
[39] Borgh I, Hedström P, Odqvist J, Borgenstam A, Ågren J, Gholinia A, Winiarski B, Withers PJ, Thompson GE, Mingard K, Gee MG. On the three-dimensional structure of WC grains in cemented carbides. Acta Metall. 2013;61:4726-33.

[40] Sheikh S, M'Saoubi R, Flasar P, Schwind M, Persson T, Yang J, Llanes L. Fracture toughness of cemented carbides: Testing method and microstructural effects. Int $\mathbf{J}$ Refract Met Hard Mater. 2015;49:153-60.

[41] Rauch E, Veron M, Portillo J, Bultreys D, Maniette Y, Nicolopoulos S. Automatic crystal orientation and phase mapping in TEM by precession diffraction. Microsc Anal. 2008;22:S5S8.

[42] Portillo J, Rauch EF, Nicolopoulos S, Gemmi M, Bultreys D. Precession electron diffraction assisted orientation mapping in the transmission electron microscope. Mater Sci Forum. 2010;644:1-7.

[43] Wu X, Tao N, Hong Y, Liu G, Xu B, Lu J, Lu K. Strain-induced grain refinement of cobalt during surface mechanical attrition treatment. Acta Metall. 2005;53:681-91.

[44] Lisovsky AF, Tkachenko NV, Kebko V. Structure of a binding phase in re-alloyed WC-Co cemented carbides. Int J Refract Met Hard Mater. 1991;10:33-6.

[45] Llanes L, Torres Y, Anglada M. On the fatigue crack growth behavior of WC-Co cemented carbides: kinetics description, microstructural effects and fatigue sensitivity. Acta Metall. 2002;50:2381-93.

[46] Christian J. The theory of transformations in metals and alloys. Materials Today. 2003;6:53.

[47] Bhaumik SK, Upadhyaya GS, Vaidya ML. A transmission electron microscopy study of WC10Co cemented carbides with modified hard and binder phases. Mater Charact. 1992;28:2419.

[48] Wu X, Tao N, Hong Y, Lu J, Lu K. $\gamma \rightarrow \varepsilon$ martensite transformation and twinning deformation in fcc cobalt during surface mechanical attrition treatment. Scr Mater. 2005;52:547-51.

[49] Noyan IC, Cohen JB. Residual stress: measurement by diffraction and interpretation, Springer-Verlag2013. 


\section{Table 1}

Table 1 Summary of Co phase microstructural features at various depth. Where SFs and nc means stacking faults and nanocrystalline grains, respectively.

\begin{tabular}{lll}
\hline Depth & Co phases & Microstructural features \\
\hline $0 \sim 1 \mu \mathrm{m}$ & almost all hcp & Nano grains formation, SFs exist in most of nc grains \\
$1 \sim 3 \mu \mathrm{m}$ & mostly hcp & Grain subdivision, high degree of deformation \\
$5 \sim 8 \mu \mathrm{m}$ & hcp and fcc & fcc to hcp transformation \\
\hline
\end{tabular}



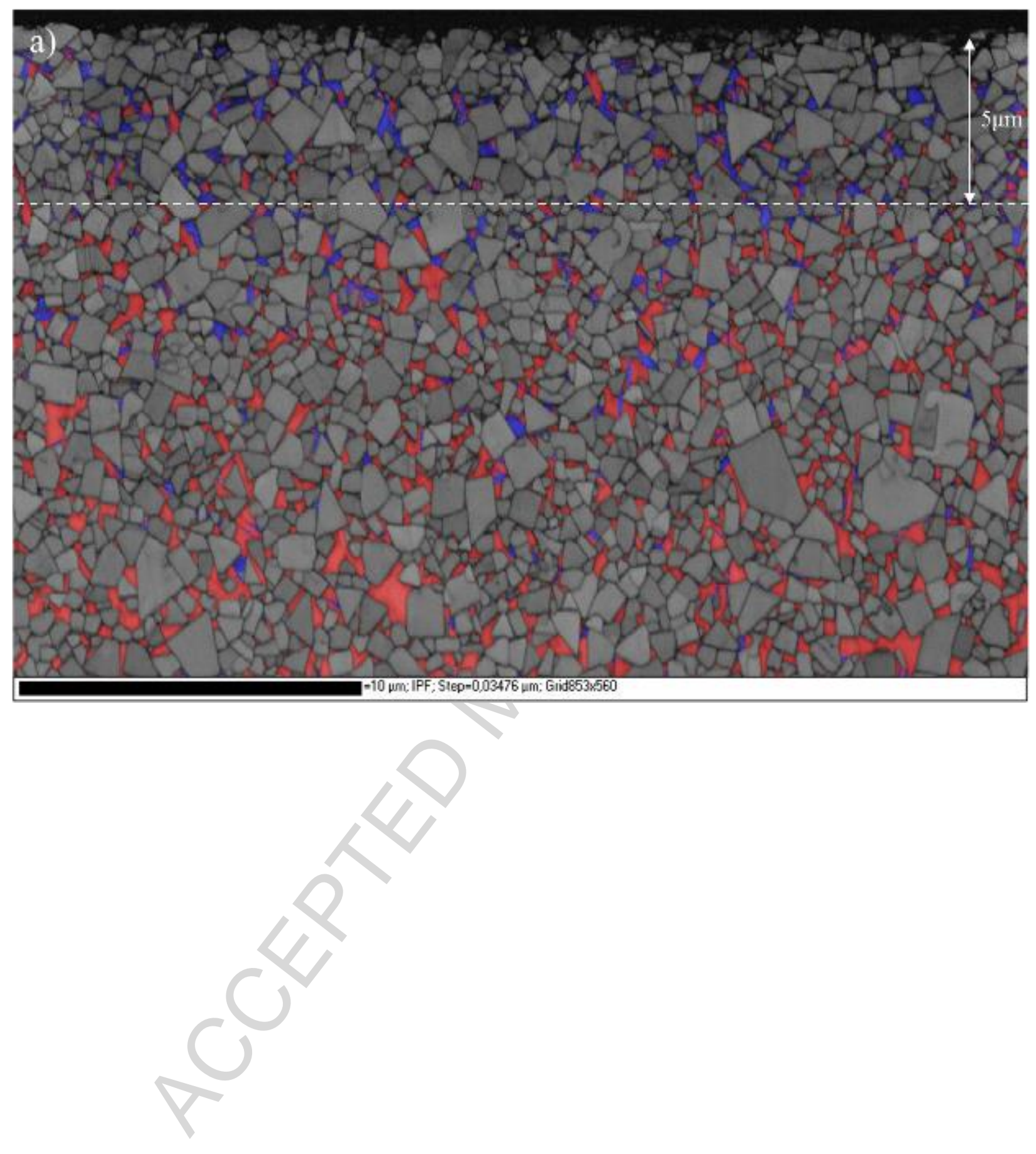


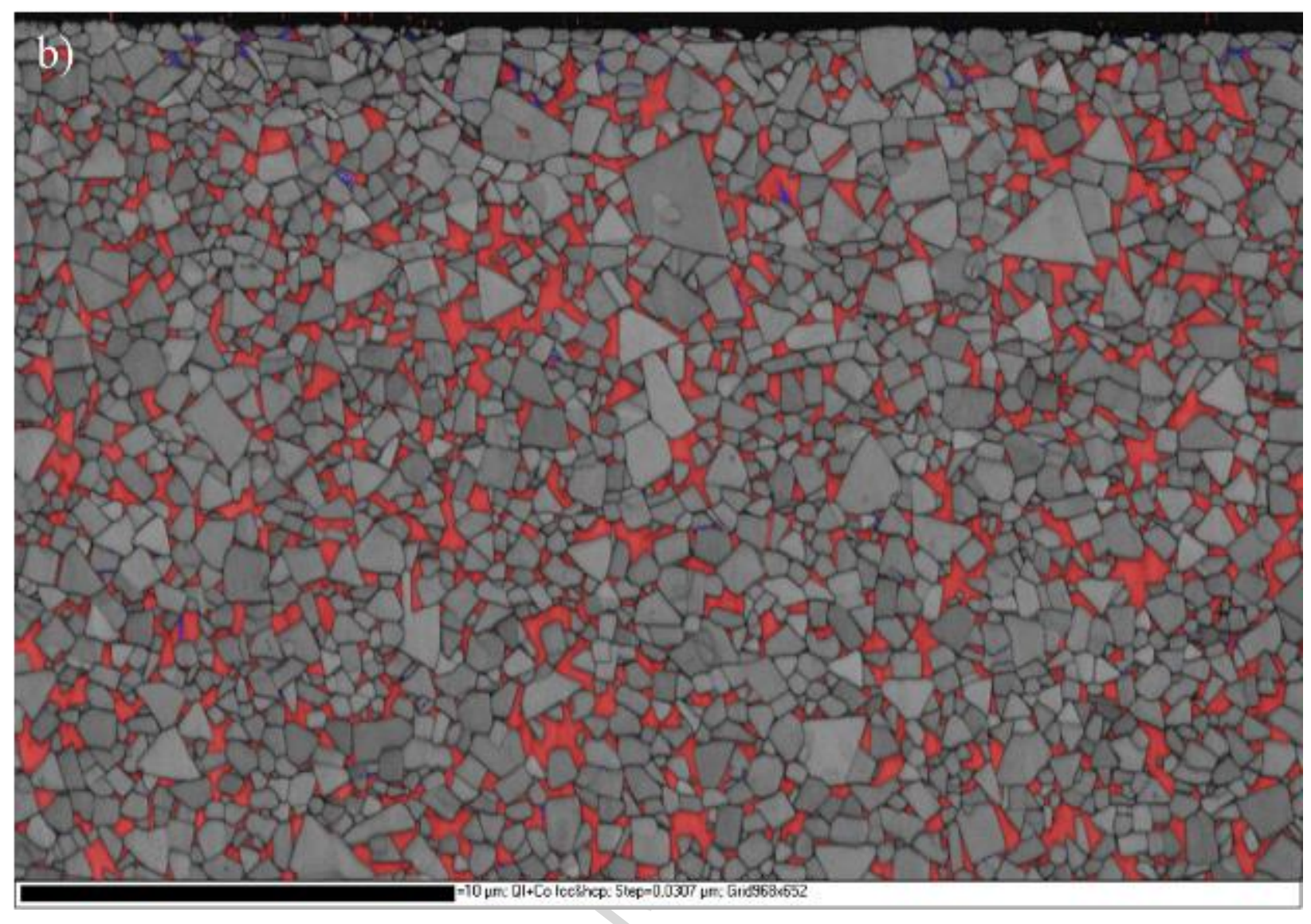

Fig. 1 EBSD phase map overlapped to the band contrast map for the metallic Co binder with red and blue colors denoting the fcc and hcp Co phase, respectively, for samples with two different surface finish: ground (a) and polished (b). Scale marker $=10 \mu \mathrm{m}$. A dashed white line was drawn in (a) to demonstrate the 0-5 $\mu \mathrm{m}$ depth region where hcp Co phase mainly detected.

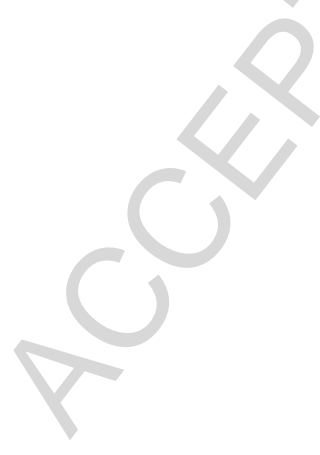




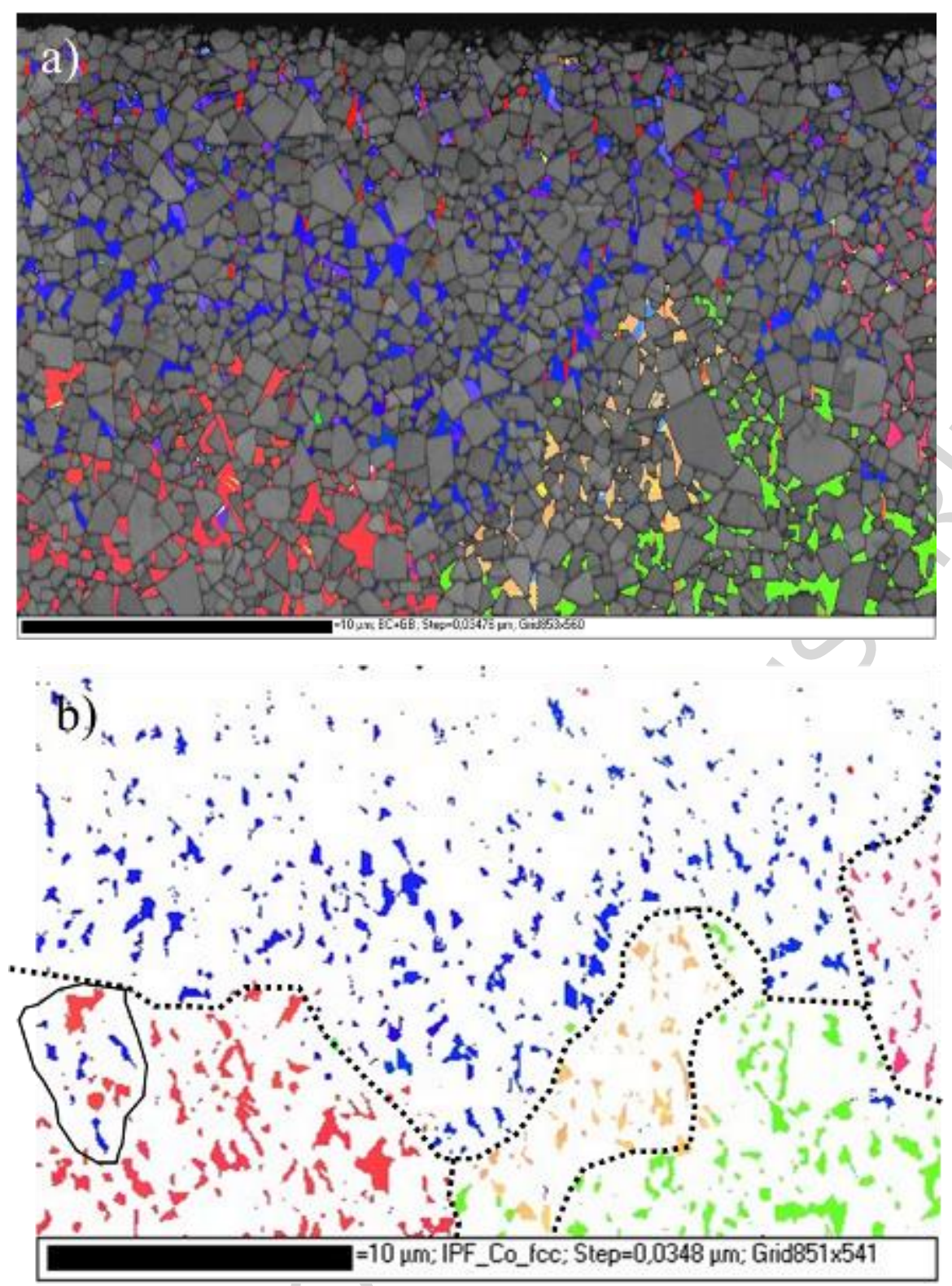




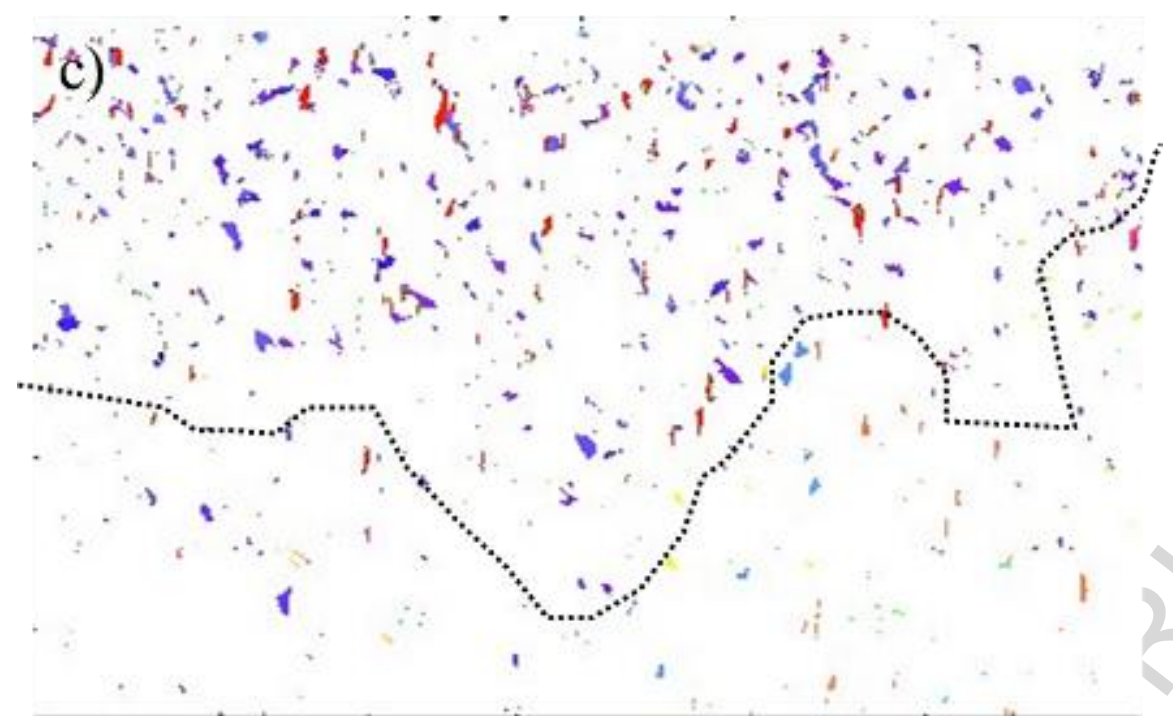

$=10 \mu \mathrm{m} ;$ MIPF_Co_hcp; Step $=0,0348 \mu \mathrm{m} ;$ Grid851×541
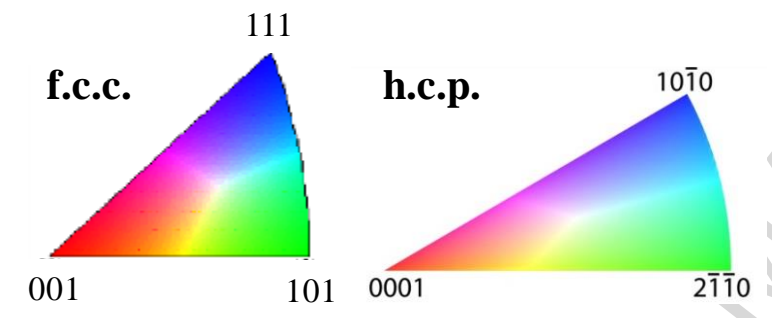

Fig. 2 EBSD analysis: Band contrast map overlapped with the IPF on the metallic Co binder phase for both possible crystallographic structures, fcc and hcp (a). Individual IPF maps for the fcc (b) and hcp phases (c), respectively. Dotted lines in (b) delineate regions with a common crystallographic orientation, whereas the dotted line in (c) is only a copy of the one which delineates the blue region in (b), aiming at a comparison purpose. 

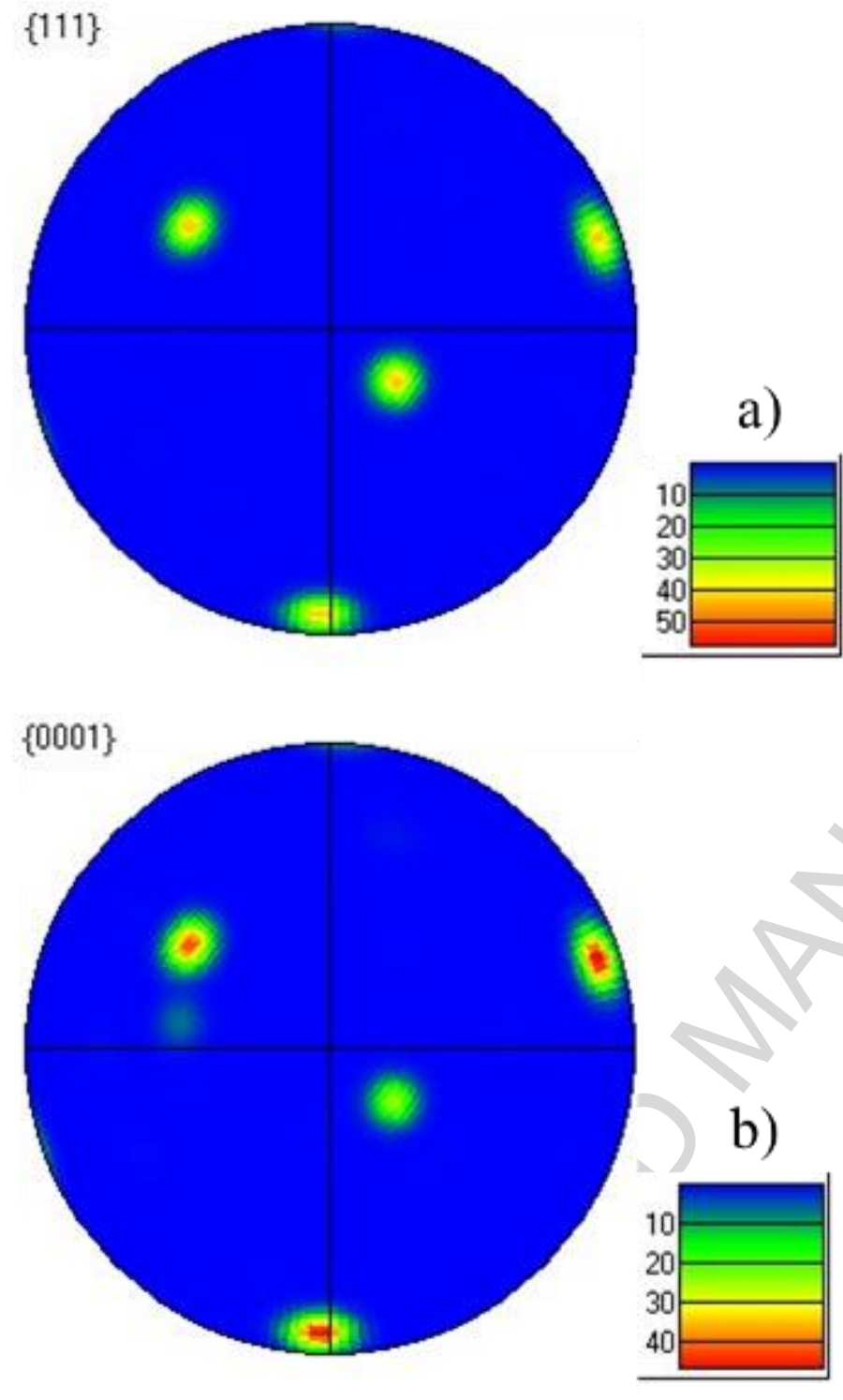

Fig. 3 PFs showing Co orientations of the cross section region (from the region directly affected by the grinding process up to $5 \mu \mathrm{m}$ depth) for the fcc $\left\{\begin{array}{lll}1 & 1 & 1\end{array}\right\}$ (a) and hep $\left\{\begin{array}{llll}0 & 0 & 0 & 1\end{array}\right\}$ orientations occurring in same directions as fcc $\left\{\begin{array}{lll}1 & 1 & 1\end{array}\right\}$ orientations (b). 


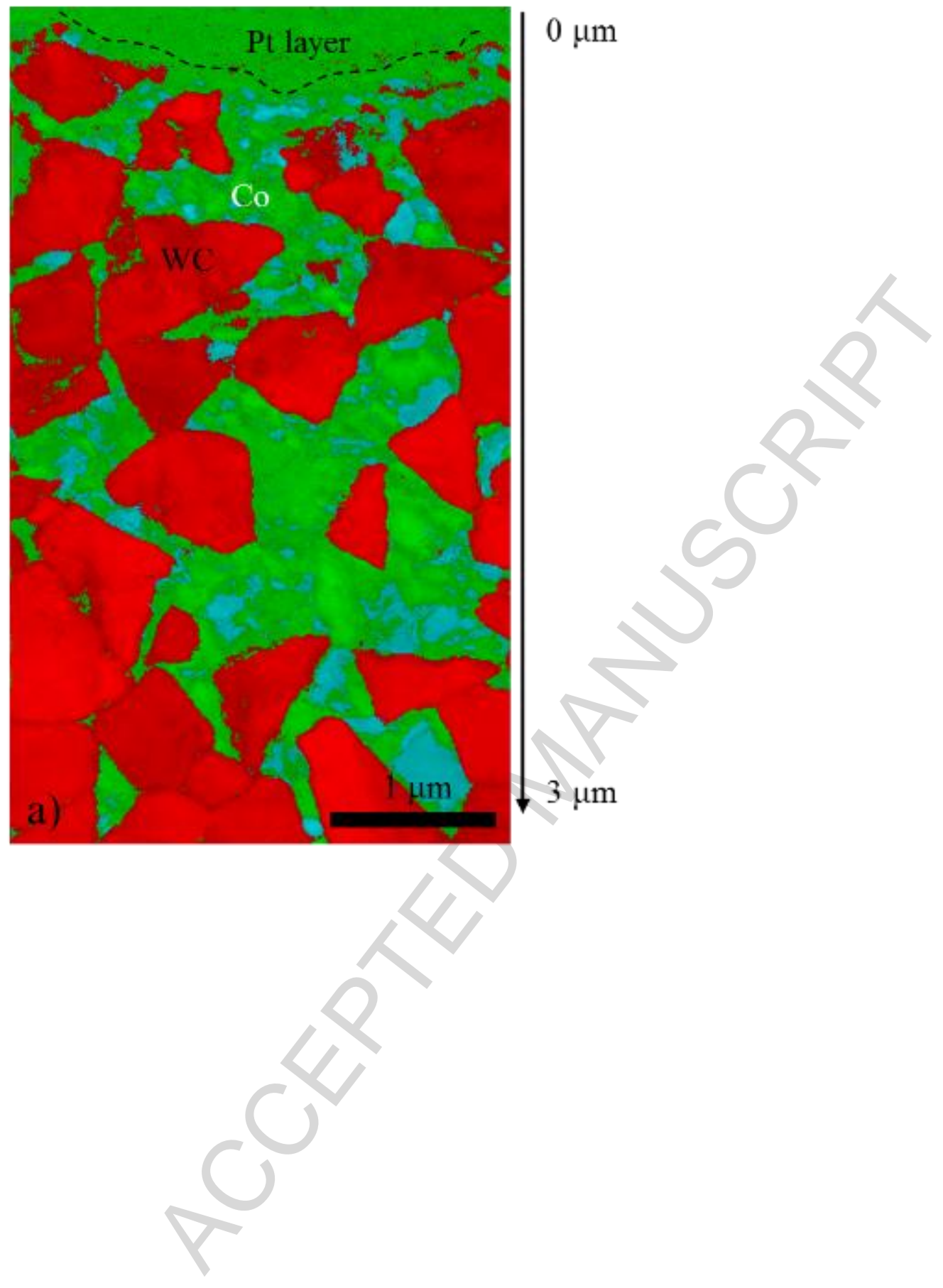




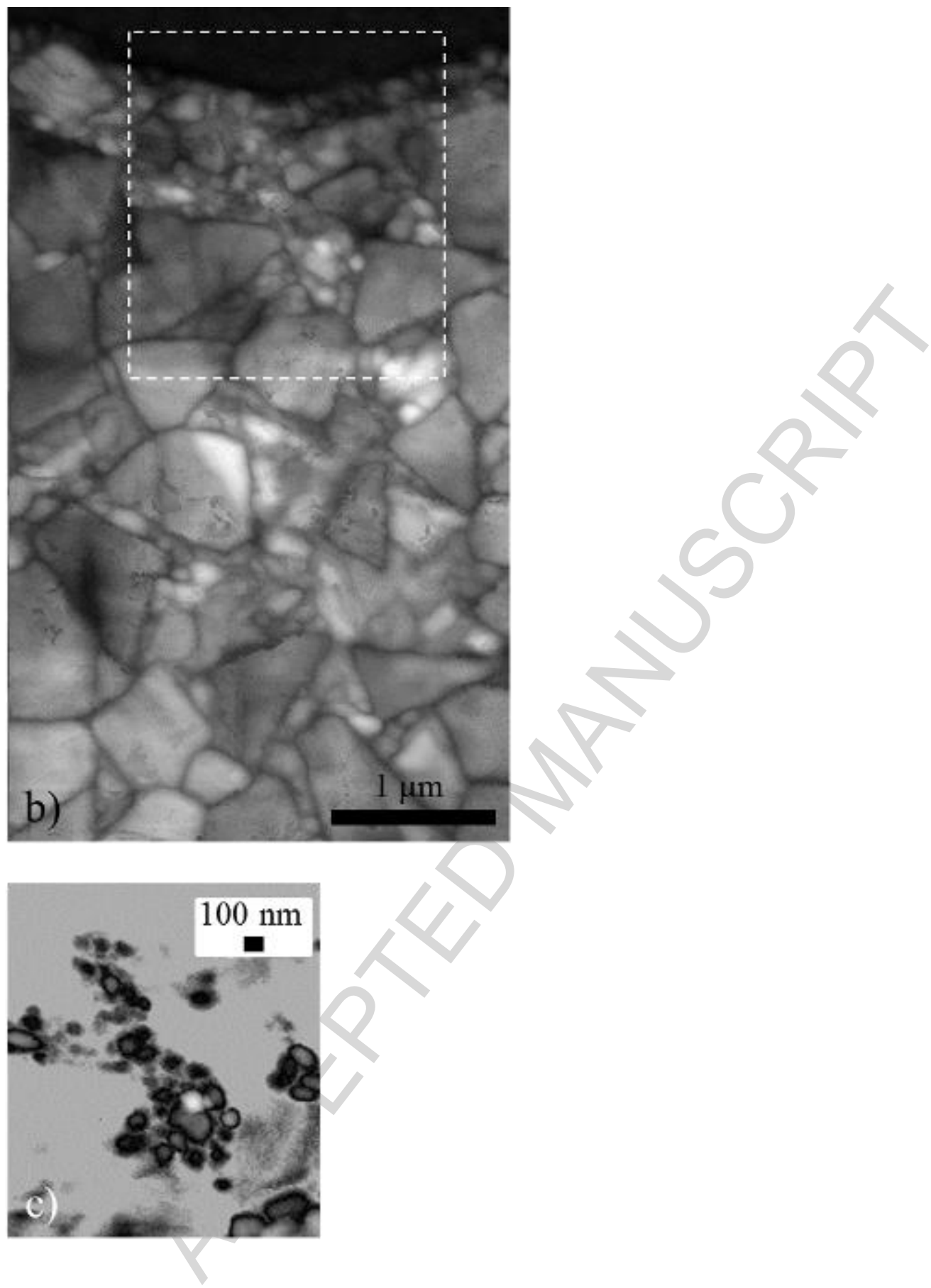




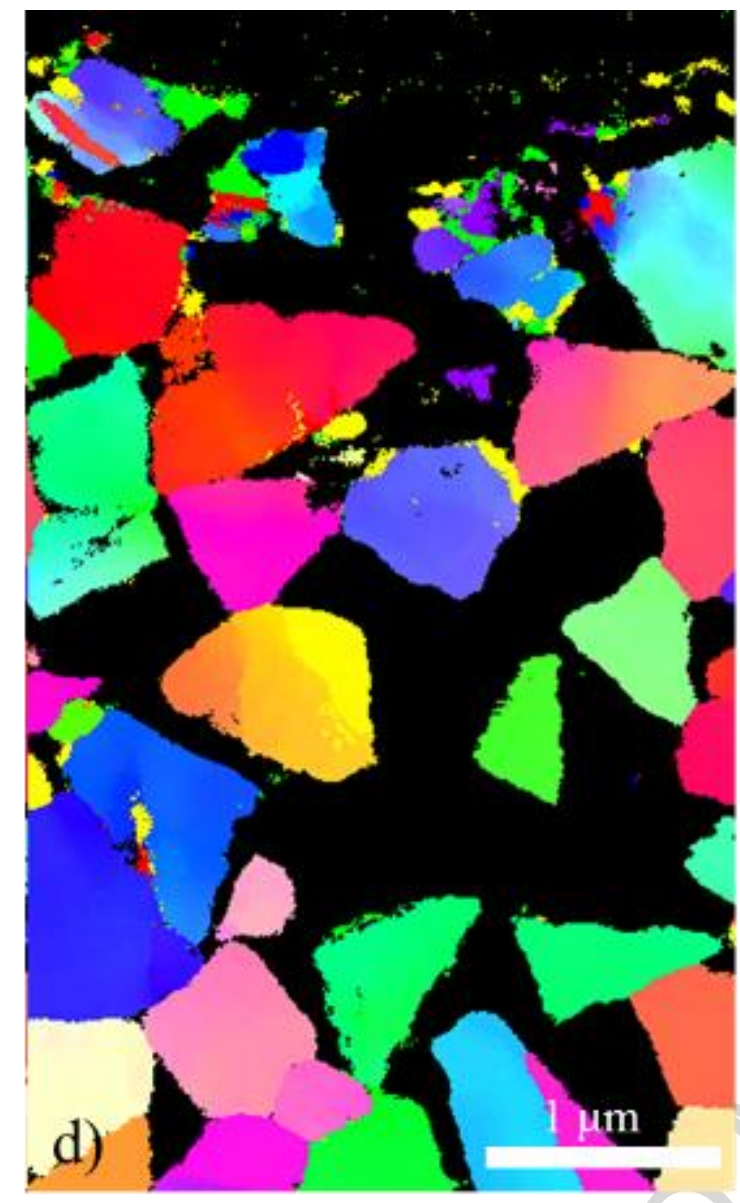

Fig. 4 Crystal orientations and phases mapping obtained from the surface to the $3 \mu \mathrm{m}$ deep subsurface region using PED-ACOM technique: phase and reliability combined map (a) indexed as WC in red, fcc Co in blue and hcp Co in green, a dotted line was drawn to distinguish the Pt protective layer from the targeted material; the correlation index map (b), an index map (c) only containing Co phase corresponding to the dotted rectangular area in (b) and orientation map of WC phase (d). 

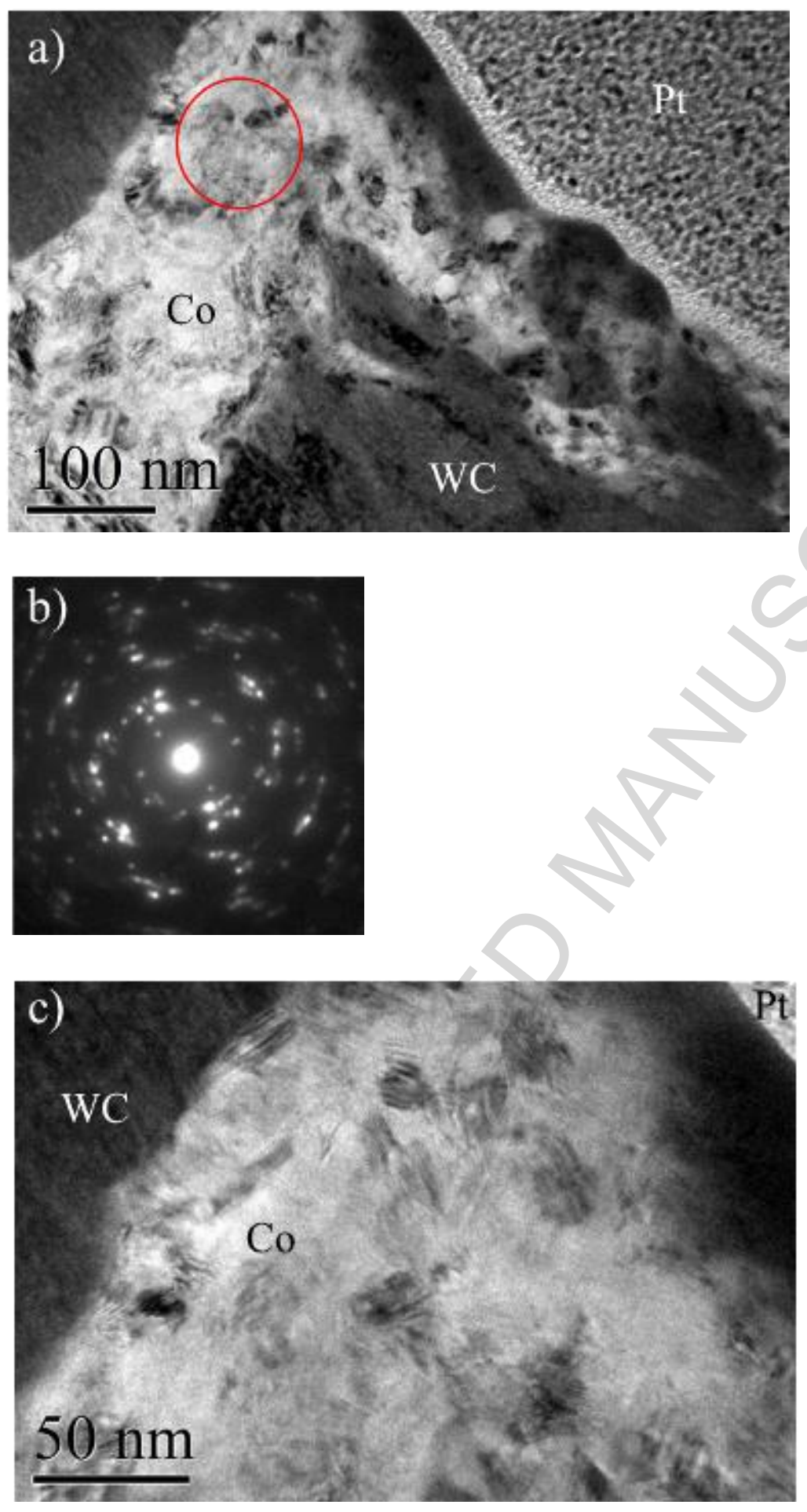


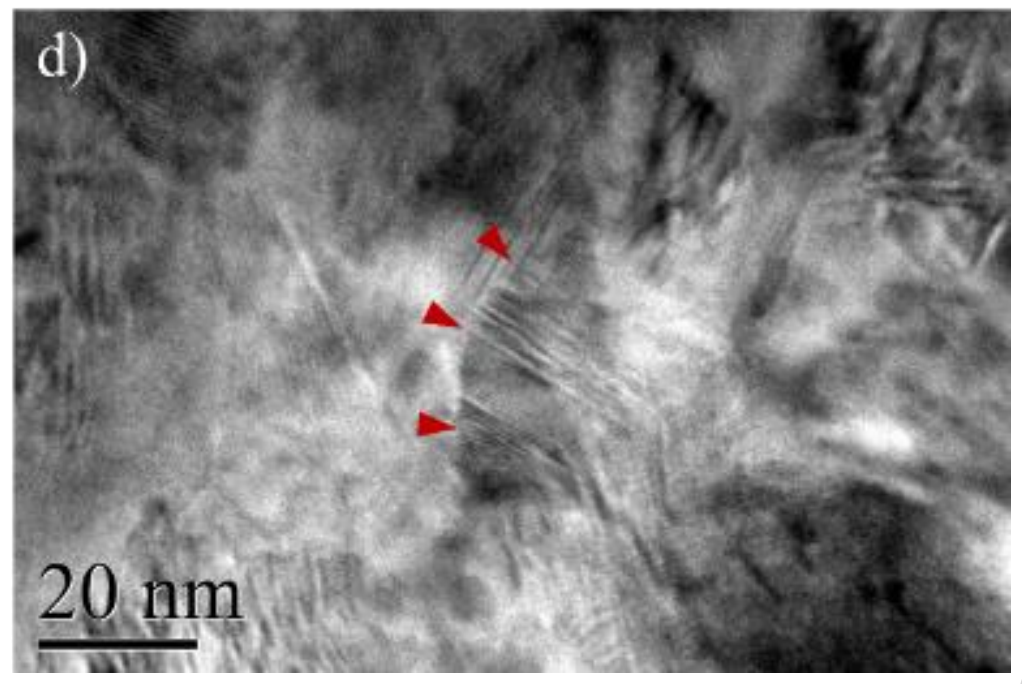

Fig. 5 TEM microstructure observation of the highly deformed Co binder in the region affected by the grinding process (a). SAED pattern (b) recorded from the area indicated by a circle in (a). Two images (c) and (d), in an increasing magnification order, exhibit the deformed Co region more clearly. 

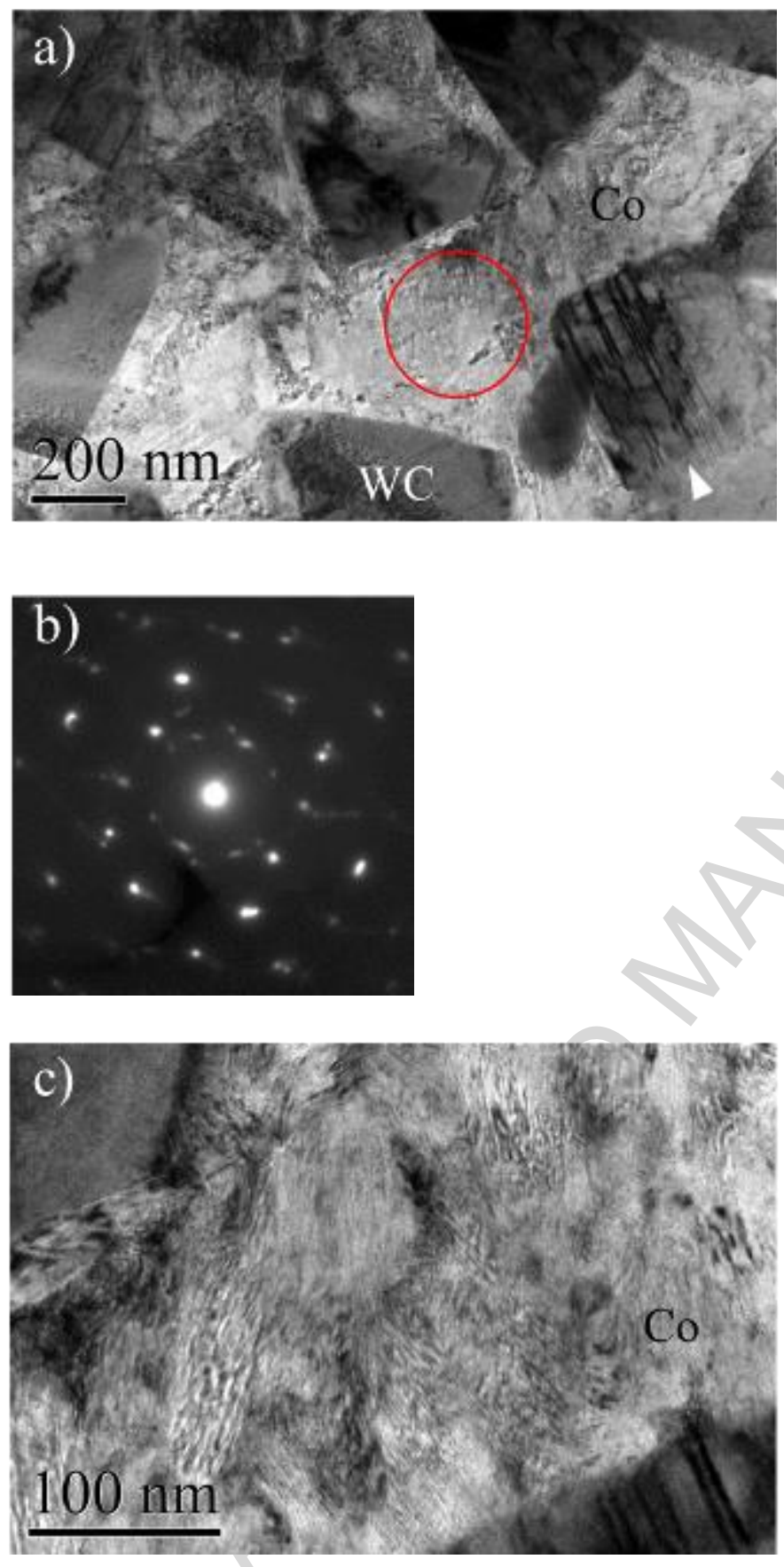

Fig. 6 TEM microstructure of the ground material at a depth of around $2 \mu \mathrm{m}$ below the surface (a). SAED pattern (b) recorded from the area indicated by a circle in (a). Image (c) shows a magnification of the deformed Co pool. 

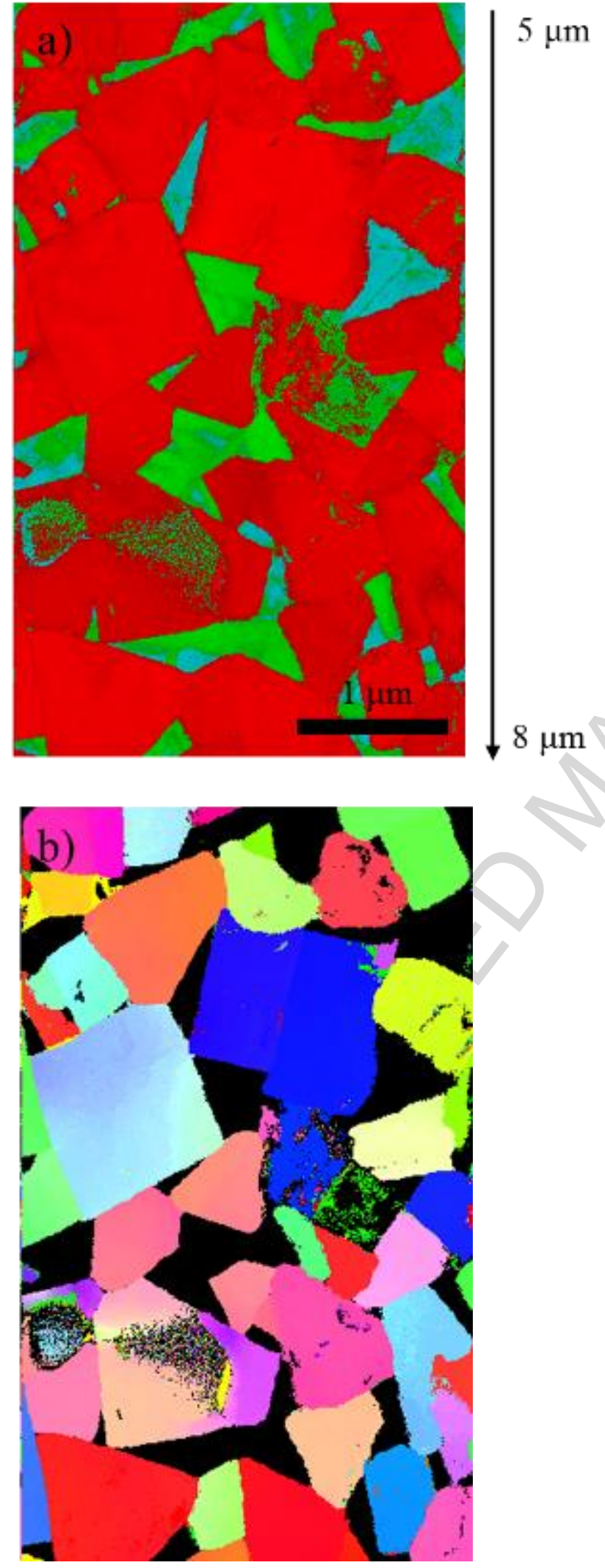

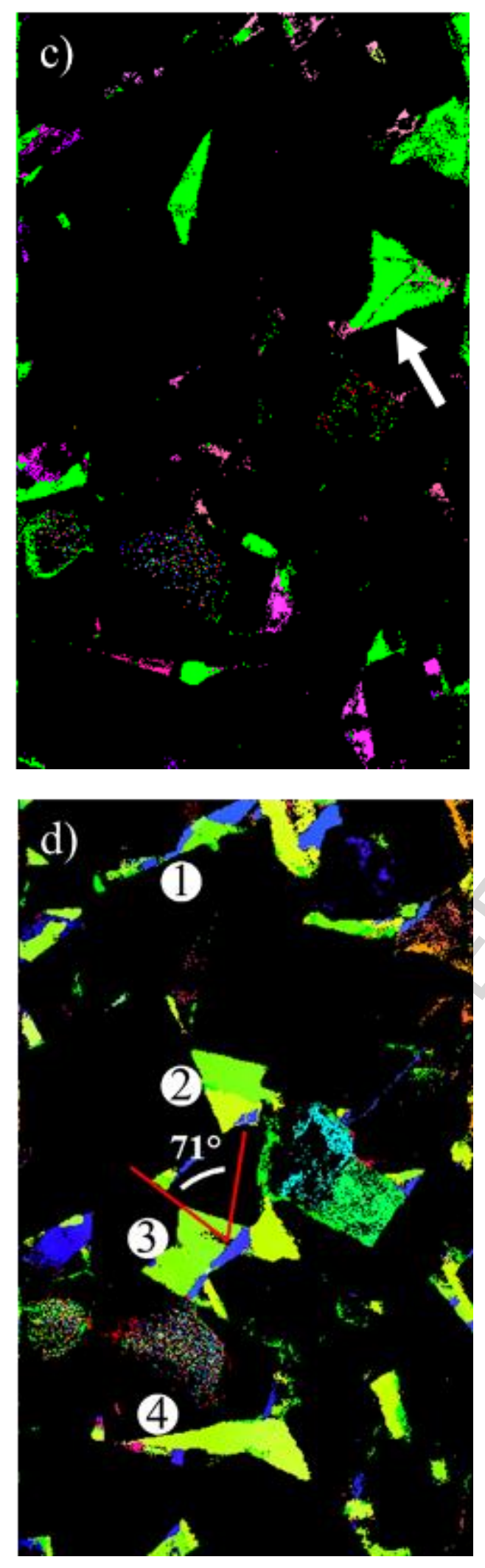


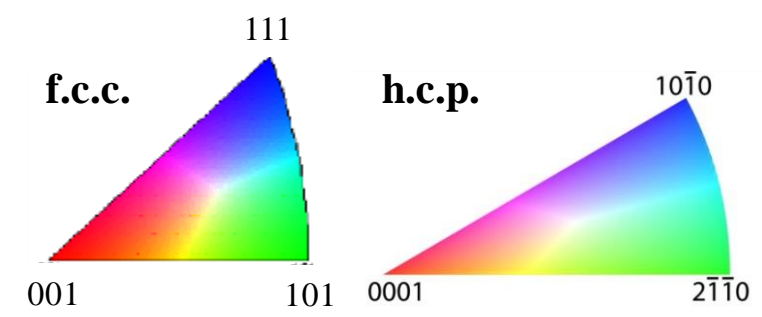

Fig. 7 Crystal orientations and phases mapping obtained from subsurface region covered $5-8 \mu \mathrm{m}$ depth using PED-ACOM technique: phase and reliability combined map indexed as WC in red, fcc Co in blue and hcp Co in green (a), orientation map of WC phase (b), fcc Co phase (c) and hcp Co phase (d). Scale marker $=1 \mu \mathrm{m}$ and uniform for all these four maps. 